\title{
Application of the AHP in Choosing Project Manager
}

\author{
Myagmarsuren Damdinsuren, Batkhishig Ishdamba
}

Doctor (Ph.D), professor, Economics and Business School of Mongolian University of Life Sciences, Mongolia Doctor (Ph.D), professor, Mongolian University of Life Science, Mongolia

\begin{abstract}
This paper presents the Analytical Hierarchy Process (AHP) as a potential decision making method for use in project management. The agricultural project contractor choosing problem is used as research object. A hierarchical structure is constructed for the prequalification criteria and the agricultural project contractor wishing to prequalify for a project. By applying the AHP, the prequalification criteria can be prioritized and a descending-order list of contractors can be made in order to select the best agricultural project contractor to perform the project. The paper presents group decisionmaking using the AHP. The AHP implementation steps will be simplified by using the 'Expert Choice' that is available commercially and designed for implementing AHP. It is hoped that this will encourage the application of the AHP by project management professionals.
\end{abstract}

Keywords- Analytical hierarchy process; AHP; Project management; agricultural project manager prequalification.

\section{INTRODUCTION}

The Analytical Hierarchy Process (AHP) is a decisionaiding method developed by Saaty [9-12] It aims at quantifying relative priorities for a given set of alternatives on a ratio scale, based on the judgment of the decisionmaker, and stresses the importance of the intuitive judgments of a decision-maker as well as the consistency of the comparison of alternatives in the decision-making process [9]. Since a decision-maker bases judgments on knowledge and experience, then makes decisions accordingly, the AHP approach agrees well with the behavior of a decision-maker. The strength of this approach is that it organizes tangible and intangible factors in a systematic way, and provides a structured yet relatively simple solution to the decision-making problems [13].

The objective of this paper is to introduce the application of the AHP in agricultural project management. The AHP's implementation steps, and demonstrates AHP application on the agricultural project manager prequalification problem. It is hoped that this will encourage its application in the whole area of project management.

\section{THE ANALYTICAL HIERARCHY PROCESS (AHP)}

Belton and Gear [1] and Dyer and Wendel [2] attacked the AHP on the grounds that it lacks a firm theoretical basis. Harker and Vargas [4] and Perez [19] discussed these major criticisms and proved with a theoretical work and examples that they are not valid. They commented that the AHP is based upon a firm theoretical foundation and, as examples in the literature and the day-to-day operations of various governmental agencies, corporations and consulting firms illustrate, the AHP is a viable, usable decision-making tool.

Saaty [9-12] developed the following steps for applying the AHP:

1. Define the problem and determine its goal.

2. Structure the hierarchy from the top (the objectives from a decision-maker's viewpoint) through the intermediate levels (criteria on which subsequent levels depend) to the lowest level which usually contains the list of alternatives.

3. Construct a set of pair-wise comparison matrices (size $n x \mathrm{n}$ ) for each of the lower levels with one matrix for each element in the level immediately above by using the relative scale measurement shown in Table 1 . The pair-wise comparisons are done in terms of which element dominates the other.

4. There are $n(n-1)$ / judgments required to develop the set of matrices in step 3. Reciprocals are automatically assigned in each pair-wise comparison.

5. Hierarchical synthesis is now used to weight the eigenvectors by the weights of the criteria and the sum is taken over all weighted eigenvector entries corresponding to those in the next lower level of the hierarchy.

6. Having made all the pair-wise comparisons, the consistency is determined by using the eigenvalue, $\mathrm{L}_{\max }$, to calculate the consistency index, $\mathrm{CI}$ as follows: 
$\mathrm{CI}=\left(1_{\max }-n\right) /(n-1)$, where $n$ is the matrix size. Judgment consistency can be checked by taking the consistency ratio (CR) ofCI with the appropriate value in Table 2. The CR is acceptable, if it does not exceed 0.10 . If it is more, the judgment matrix is inconsistent. To obtain a consistent matrix, judgments should be reviewed and improved.

7. Steps 3-6 are performed for all levels in the hierarchy.

Table.1: Pair-wise comparison scale for AHP preferences [24-27]

Numerical rating Verbal judgments of

\begin{tabular}{r} 
preferences \\
\hline 9 \\
8 \\
7 \\
6 \\
5 \\
4 \\
3 \\
2 \\
1
\end{tabular}

strategies and the factors that influence the process. They reported five methods that they found in use for contractor prequalification: dimensional weighting, two-step prequalification, dimension-wide strategy, prequalification formula, and subjective judgment.

In the dimensional weighting method [7], the choice selection criteria and their weights are dependent on the owner. All contractors are ranked on the basis of the criteria. A contractor's total score is calculated by summing their ranks multiplied by the weight of the respective criteria. Then, contractors are ranked on the basis of their total scores, and this rank order of the contractors is used for prequalification. The problem with this method is 9 Extredidingftreedeight of the respective criteria, something for 8 Very strow

Very strphel iwarefefepreqfequalification method [7] is a modification Strongly to very strongly
Stronfoly phefeflmedsional weighting method. In the irst step,

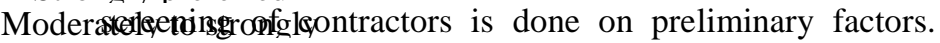
Moderntely arefererged through this step to be eligible for the second Equally to moderately Equally preferred hting technique is used for more

Table.2: Average random consistency (RI) [24-27] specialized factors

\begin{tabular}{|c|c|c|c|c|c|c|c|c|c|c|}
\hline $\begin{array}{c}\text { Size of } \\
\text { matrix }\end{array}$ & 1 & 2 & 3 & 4 & 5 & 6 & 7 & 8 & 9 & 10 \\
\hline $\begin{array}{c}\text { Rando } \\
\mathrm{m} \\
\text { consiste } \\
\text { ncy }\end{array}$ & 0 & 0 & 0. & 0. & 1. & 1. & 1. & 1. & 1. & 1. \\
\hline
\end{tabular}

In dimension-wide strategy method [7], a list of the most important prequalification criteria is developed in descending order depending on how important the criterion is. Contractors are then evaluated on these factors. If a candidate fails to meet any

\section{III. \\ THE AHP IN AGRICULTURAL PROJECT MANAGEMENT}

In this paper, agricultural project manager prequalification (an evaluation problem) will be used as an example of the possibility of using AHP in project management. Prequalification is defined by Moore [6] as the screening of agricultural project manager by project owners or their representatives according to a predetermined set of criteria deemed necessary for successful project performance, in order to determine the managers' competence or ability to participate in the project bid.

A number of studies have focused on agricultural project manager prequalification. Lower [5] reviewed the guidelines of the prequalification process in different States in the US. He also discussed how prequalification can provide the owner with appropriate facilities representing an effective and efficient expenditure of money.

Russel and Skibniewski [8] tried to describe the contractor prequalification process along with the decision-making of the criteria, the candidate is removed from the prequalification process.

The prequalification formula method [7] prequalifies contractors on the basis of a formula that calculates the maximum capability of a contractor. The maximum capability is defined as the maximum amount of uncompleted work in progress that the contractor can have at any one time. In this method, the contractor's prequalification is dependent on the contractor's maximum capability, current uncompleted work and the size of the project under consideration. If the difference between the contractor's capability and current uncompleted work is less than the project works, then the contractor is removed from the bidding process.

The previous methods were devised with a common goal to introduce an efficient and systematic procedure for contractor prequalification. In some instances, owners may base their contractor selection decision on subjective judgment and not on a structured approach. The judgment 
may be influenced by owner biases, such as previous experience with the contractor or how well the contractor's field staff operates.

Russel [7] analyzed contractor failure in the US and recommended that an owner should have two means of avoiding or minimizes the impact of contractor failure: (1) analyzing the contractor qualification prior to contract award; and (2) monitoring the contractor's performance after contract award.

\section{SURVEY}

A simplified agricultural project /wheat production project/ survey of contractor prequalification will be demonstrated here for illustration purposes. To simplify calculations, the factors that will be used in the project example for prequalification are experience, financial stability, quality performance, manpower resources, equipment resources, and current workload. Other criteria can be added if necessary, together with a suggestion that a computer be used to simplify calculations. Table 3 presents a project example for which contractors I, II, III, IV and V wish to prequalify. An argument could be presented that contractor $\mathrm{V}$ is not meeting the minimum criteria. Descriptions presented in Table 3 under 'Contractor V', such as 'bad organization' and 'unethical techniques', qualify him for immediate elimination from the list by the project owner. This is quite consistent with the method 'elimination by aspect' suggested by Tversky [14]. Nevertheless, it is the choice of the decision-maker to eliminate contractor $\mathrm{V}$ immediately since he/she does not meet the minimum criteria. Contractor V could be left on the list (the choice in this paper for demonstration purposes) so that he appears at the end of the list of 'best contractors in descending order', as will be shown at the end of the example. The matter is safeguarded by checking the consistency of the pair-wise comparison which is a part of the AHP procedure.

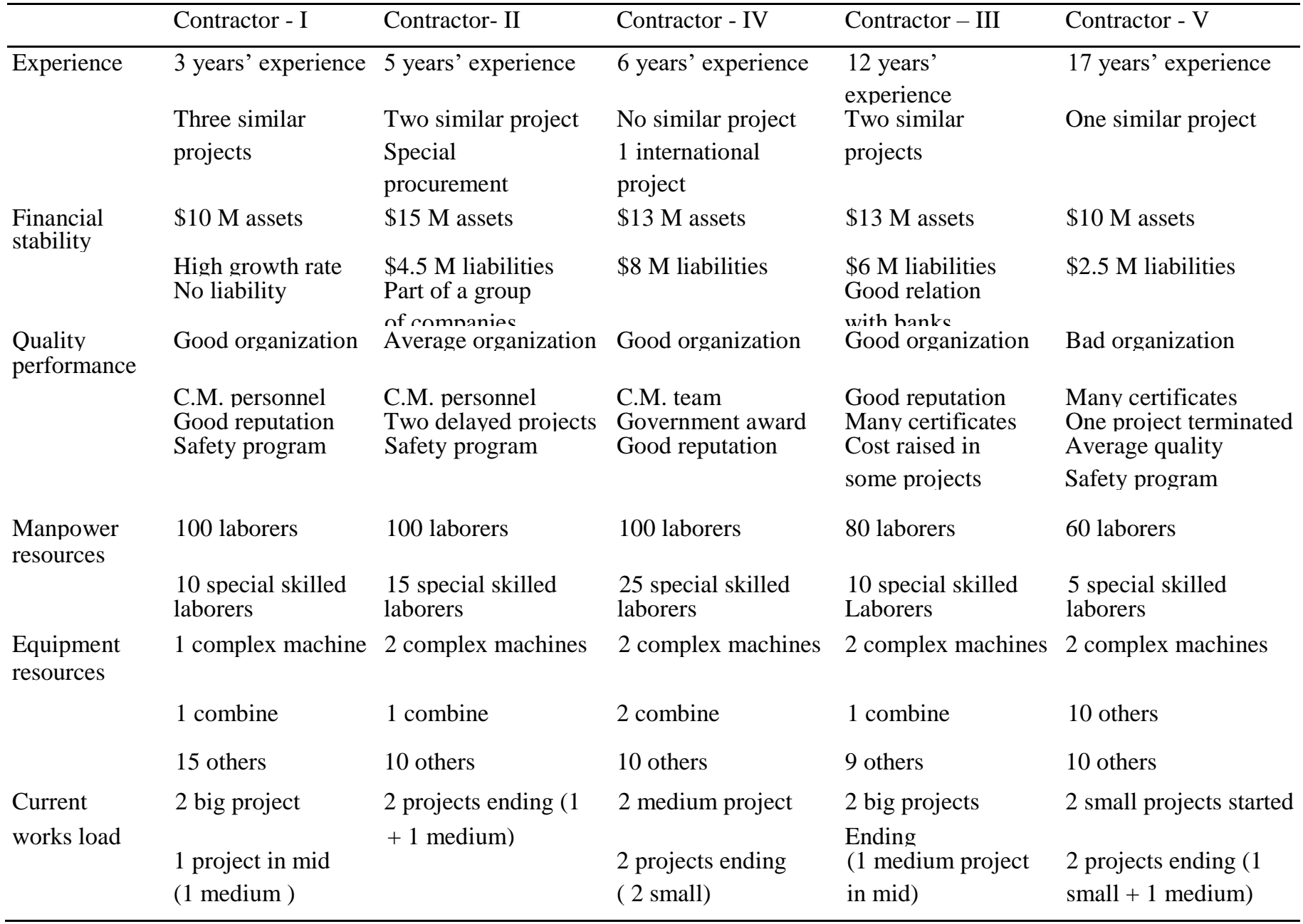


The AHP procedure described in the hierarchy of the problem can be developed, shown in Fig 1. For step 3, the decision-makers have to indicate preferences or priority for each decision alternative in terms of how it contributes to each criterion as shown in Table 4.

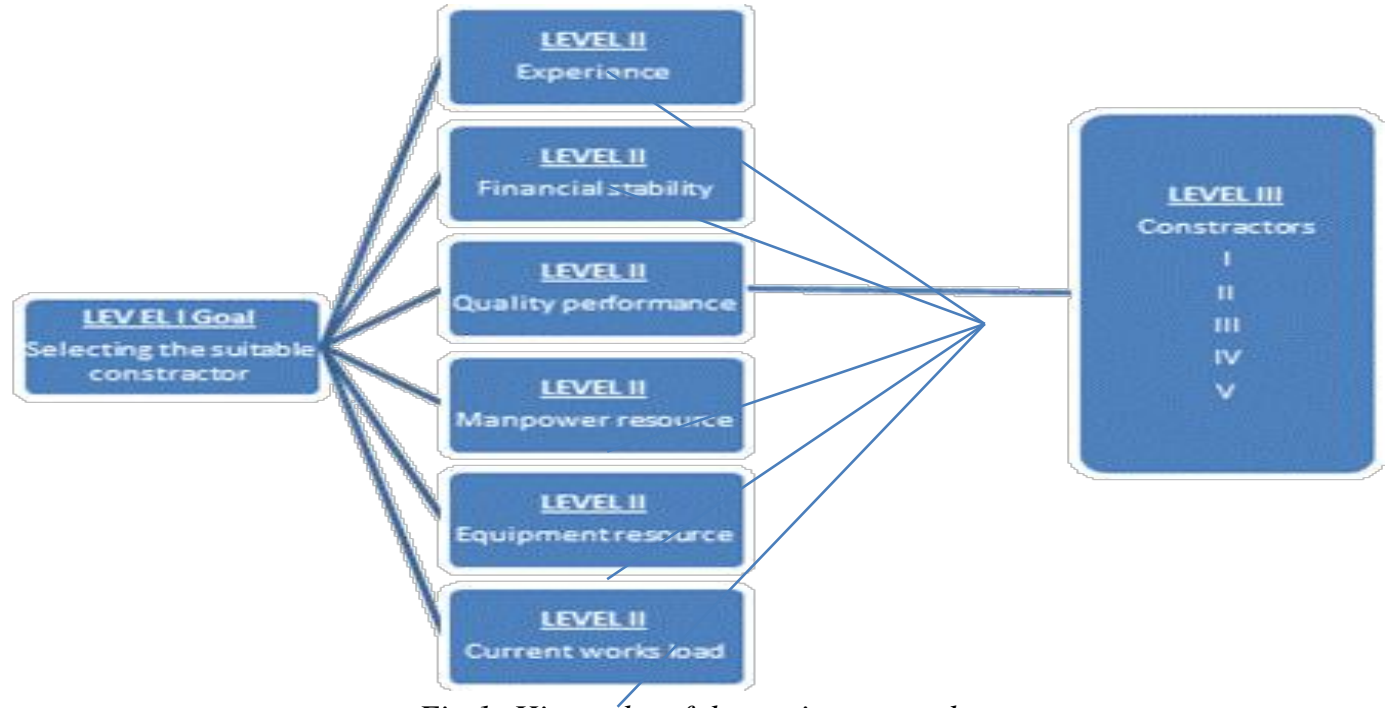

Fig.1: Hierarchy of the project example

Key of remark: Exp = Experience, F.S = Financial Stability, QP = Quality Performance, M.P.R =Manpower Resources, E.R = Equipment Resources, CW.L = Current Works Load

I, II, III, IV and V are the contractors being prequalified.

And, the following can be done automatically by the AHP software, by Expert Choice:

1. synthesizing the pair-wise comparison matrix;

2. calculating the priority vector for a criterion such as experience;

3. calculating the consistency ratio;

4. calculating $\mathrm{A}_{\max }$;

5. calculating the consistency index, $\mathrm{CI}$;

6. Selecting appropriate value of the random consistency ratio from Table 2; and checking the consistency of the pair-wise comparison matrix to check whether the decision-maker's comparisons were consistent or not.

The calculations for these items will be explained next for illustration purposes. Synthesizing the pair-wise comparison matrix is performed by dividing each element of the matrix by its column total. For survey, the value 0.08 in Table 5 is obtained by dividing 1 (from Table 4) by 12.5 , the sum of the column items in Table $4(1+3+2+6+$ $1 / 2)$.

Table.4: Pair-wise comparison matrix for experience

\begin{tabular}{|c|c|c|c|c|c|}
\hline Experience & I & II & III & IV & V \\
\hline I & 1 & $1 / 3$ & $1 / 2$ & $1 / 6$ & 3 \\
\hline II & 3 & 1 & 2 & $1 / 2$ & 4 \\
\hline III & 2 & $1 / 2$ & 1 & $1 / 3$ & 3 \\
\hline IV & 6 & 2 & 3 & 1 & 7 \\
\hline V & $1 / 3$ & $1 / 4$ & $1 / 3$ & $1 / 7$ & 1 \\
\hline
\end{tabular}

The priority vector in Table 5 can be obtained by finding the row averages. For example, the priority of contractor I with respect to the criterion 'experience' in Table 5 is calculated by dividing the sum of the rows $(0.08+0.082+$ $0.073+0.078+0.118)$ by the number of contractors (columns), i.e., 5, in order to obtain the value 0.086. The priority vector for experience, indicated in Table 5 , is given below. /0.086, 0.249, 0.152, 0.457, 0.055/

Estimating the consistency ratio is as follows: 
Table.5: Synthesized matrixes for experience

\begin{tabular}{|c|c|c|c|c|c|c|}
\hline & I & II & III & IV & V & Priority vector \\
\hline I & 0.08 & 0.082 & 0.073 & 0.078 & 0.118 & 0.086 \\
\hline II & 0.24 & 0.245 & 0.293 & 0.233 & 0.235 & 0.249 \\
\hline III & 0.16 & 0.122 & 0.146 & 0.155 & 0.175 & 0.152 \\
\hline IV & 0.48 & 0.489 & 0.439 & 0.466 & 0.412 & 0.457 \\
\hline V & 0.04 & 0.061 & 0.049 & 0.066 & 0.059 & 0.055 \\
\hline
\end{tabular}

$\boldsymbol{\lambda}_{\text {max }}=5.037, \mathrm{CI}=0.00925, \mathrm{RI}=1.12, \mathrm{CR}=0.0082<0.1 \mathrm{OK}$

Other criteria's synthesized matrix and priority vector's result shown as table 6. /Calculation is same as synthesized matrix for experience/

Table.6: Priority vectors other criteria

\begin{tabular}{|c|c|c|c|c|c|c|}
\hline Contractors & & I & II & III & IV & $\mathrm{V}$ \\
\hline \multirow[t]{2}{*}{ Financial stability } & Priority vectors & 0.491 & 0.079 & 0.144 & 0.283 & 0.045 \\
\hline & \multicolumn{6}{|c|}{$\boldsymbol{\lambda}_{\text {max }}=5.34 ; \mathrm{CI}=0.06 ; \mathrm{RI}=1.12 ; \mathrm{CR}=0.063<0.1 \mathrm{OK}$} \\
\hline \multirow[t]{2}{*}{ Quality performance } & Priority vectors & 0.289 & 0.073 & 0.501 & 0.167 & 0.35 \\
\hline & \multicolumn{6}{|c|}{$\boldsymbol{\lambda}_{\text {max }}=5.38 ; \mathrm{CI}=0.085 ; \mathrm{RI}=1.12 ; \mathrm{CR}=0.079<0.1 \mathrm{OK}$} \\
\hline \multirow[t]{2}{*}{ Manpower resource } & Priority vectors & 0.149 & 0.327 & 0.444 & 0.083 & 0.345 \\
\hline & \multicolumn{6}{|c|}{$\boldsymbol{\lambda}_{\text {max }}=5.24 ; \mathrm{CI}=0.069 ; \mathrm{RI}=1.12 ; \mathrm{CR}=0.063<0.1 \mathrm{OK}$} \\
\hline \multirow[t]{2}{*}{ Equipment resource } & Priority vectors & 0.090 & 0.301 & 0.601 & 0.062 & 0.039 \\
\hline & \multicolumn{6}{|c|}{$\boldsymbol{\lambda}_{\text {max }}=5.23 ; \mathrm{CI}=0.081 ; \mathrm{RI}=1.12 ; \mathrm{CR}=0.06420 .1 \mathrm{OK}$} \\
\hline \multirow[t]{2}{*}{ Current work load } & Priority vectors & 0.201 & 0.603 & 0.169 & 0.081 & 0.071 \\
\hline & \multicolumn{6}{|c|}{$\boldsymbol{\lambda}_{\text {max }}=5.3 ; \mathrm{CI}=0.09 ; \mathrm{RI}=1.12 ; \mathrm{CR}=0.079<0.1 \mathrm{OK}$} \\
\hline
\end{tabular}

Table.7: Pair wise comparison matrix for six criteria

\begin{tabular}{|c|c|c|c|c|c|c|c|c|c|}
\hline & Exp & FS & QP & MPR & ER & CWL & PV & PA & PA/PV \\
\hline Exp & 1 & 2 & 3 & 6 & 6 & 4 & 0.3511 & 2.3418 & 6.6708 \\
\hline FS & 0.5 & 1 & 6 & 6 & 6 & 4 & 0.3183 & 2.2925 & 7.2028 \\
\hline QP & 0.33 & 0.167 & 1 & 4 & 4 & 3 & 0.1482 & 0.9556 & 6.4491 \\
\hline MPR & 0.17 & 0.167 & 0.25 & 1 & 2 & 0.5 & 0.0523 & 0.3223 & 6.1599 \\
\hline ER & 0.17 & 0.167 & 0.25 & 0.5 & 1 & 0.25 & 0.0375 & 0.2355 & 6.2728 \\
\hline CWL & 0.25 & 0.25 & 0.33 & 2.0 & 4 & 1 & 0.0926 & 0.5641 & 6.0902 \\
\hline Sum & 2.4167 & 3.7500 & 10.8333 & 19.5000 & 23.0000 & 12.7500 & 1 & Lmax $=$ & 6.4743 \\
\hline
\end{tabular}

Table.8: Priority matrix for constractor prequalification

\begin{tabular}{|c|c|c|c|c|c|c|c|c|}
\hline & Exp & FS & QP & MPR & ER & CWL & $\begin{array}{c}\text { Overall } \\
\text { priority } \\
\text { vector }\end{array}$ & Rank \\
\cline { 2 - 8 } & 0.3511 & 0.3183 & 0.1482 & 0.0523 & 0.0375 & 0.0926 & 0.4526 & 4 \\
\hline I & 0.086 & 0.491 & 0.289 & 0.149 & 0.09 & 0.201 & 0.361 & 2 \\
\hline II & 0.249 & 0.079 & 0.073 & 0.327 & 0.301 & 0.603 & 0.5699 & 2 \\
\hline
\end{tabular}




\begin{tabular}{|c|c|c|c|c|c|c|c|c|}
\hline III & 0.152 & 0.144 & 0.501 & 0.444 & 0.601 & 0.169 & 0.7080 & 1 \\
\hline IV & 0.457 & 0.283 & 0.167 & 0.083 & 0.062 & 0.081 & 0.4204 & 5 \\
\hline V & 0.055 & 0.045 & 0.35 & 0.345 & 0.039 & 0.071 & 0.4909 & 3 \\
\hline
\end{tabular}

For prequalification purposes, the contractors are now ranked according to their overall priorities, as follows: III, II, V, I, and IV, indicating that III is the best qualified contractor to perform the project.

Expert Choice does provide facilities for performing sensitivity analysis, where the decision-maker can check the sensitivity of his judgments on the overall priorities of contractors by trying different values for his comparison judgments.

\section{SUMMARY}

Project management involves complex decision making situations that require discerning abilities and methods to make sound decisions. The paper has presented the AHP as a decision-making method that allows the consideration of multiple criteria. The survey of contractor prequalification was created to demonstrate AHP usage in project management. Contractor prequalification involves criteria and priorities that are determined by owner requirements and preferences as well as the characteristics of the individual contractors. AHP allows group decision-making. The method can also be implemented on computer.

\section{REFERENCES}

[1] Belton V, Gear T. On a shortcoming of Saaty's method of analytical hierarchy. Omega 1983;11(3):228-30.

[2] Dyer JS, Wendel RE. A critique of the analytical hierarchy process. Working Paper 84/85-4-24, Department of Management, The University of Texas at Austin, 1985

[3] Kamal M. Al-Subhi Al-Harbi, Application or the AHP in project management, International journal of Project management 19 (2001) 19-27

[4] Harker PT, Vargas LG. The theory of ratio scale estimation: Saaty's analytic hierarchy process. Management Science 1987;33(1):1383-403.

[5] Lower J. Prequalifying construction contractors. American Water Works Association Journal 1982;74:220-3

[6] Moore MJ. Selecting a contractor for fast-track projects: Part I, principles of contractor evaluation. Plant Engineering 1985;39:74-5

[7] Russell JS, Skibniewski M. A structured approach to the contractor prequalification process in the USA.
CIB-SBI Fourth Int. Sym. on Building Economics, Session D:240-51Danish Building ResearchCopenhagen, Denmark.

[8] Russell JS, Skibniewski MJ. Decision criteria in contractor prequalification. Journal of Management in Engineering, ASCE 1988;4(2):148-64.

[9] Saaty TL. The analytic hierarchy process. New York: McGraw-Hill, 1980.

[10] Saaty TL. Decision making for leaders. Belmont, California: Life Time Leaning Publications, 1985.

[11] Saaty TL. How to make a decision: the analytic hierarchy process. European Journal of Operational Research, North-Holland 1990;48:9-26.

[12] Saaty TL, Kearns KP . Analytical planning: the organization of systems. The analytic hierarchy process series 1991; vol. 4RWS PublicationsPittsburgh, USA.

[13] Skibniewski MJ, Chao L. Evaluation of advanced construction technology with AHP method. Journal of Construction Engineering and Management, ASCE 1992;118(3):577-93.

[14] Tversky A. Elimination by aspects: a theory of choice. Psychological Review 1972;79(4):281-99. 